\title{
Modelling of On-Site Energy Consumption Profile in Construction Sites and a Case Study of Earth Moving
}

\author{
Kyoo-Jin $\mathrm{Yi}^{1}$
}

Accepted February 1, 2013

\begin{abstract}
The annual expenditure on diesel oil and heavy oil in the construction sector is the second largest among all industrial sectors. According to the greenhouse reduction scheme of Korean Government, construction sector targeted 7.1\% reduction by 2020. Although this target is not higher than other industrial sectors, it is not easy to achieve the reduction target without radical advance in technology, which cannot be expected to happen soon, considering the conservative characteristics of construction industry. Most researches on environmental issues focus on the issues related to energy saving matters during material production stage or maintenance stage, such as heating and insulation, and few deal with the issues directly related to the energy use in the construction sites. This research regards the operation of equipment for the on-site construction processes as a system and attempts to model the energy use processes related to the activities in construction sites, and provides simulation results of earth excavation and hauling processes. The result of this research is expected to aid construction planners estimating the time-based patterns of energy use and assessing greenhouse gas emission and to help selecting more energy efficient alternatives at the planning stage.
\end{abstract}

Keywords: Energy consumption, System dynamics, Simulation, Scheduling

\section{INTRODUCTION}

As matters for carbon emission reduction are becoming worldwide concerns, Korean Government announced $30 \%$ carbon emission reduction plan by 2020 , and construction sector targets $7.1 \%$ BAU reduction by 2020. This $7.1 \%$ reduction target of construction sector is relatively lower than the average reduction target of $30 \%$, but it will not be easy to achieve the target due to the following reasons:

Firstly, since technology development takes place in comparatively slower speed, it is not easy to develop energy efficient methods in construction industry. Secondly, because of the conservative nature of construction industry, it will not be simple to urge engineers to adopt more energy efficient alternatives than conventional ones, as it means giving up their long-time practised methods. Thirdly, according to the Korean Statistical Information Service (KSIS), construction sector is the second largest consumer of diesel oil among all industrial sectors and most construction equipment consumes diesel energy. Since number of skilled workers is decreasing, labour costs rises, and more equipment replaces manual labour, the amount of diesel consumption in construction sector will not be easily decreased in a short period. KSIS shows the figure that the annual amount of energy use has increased in construction sector for years, while it decreases in most industrial sectors. Therefore, achieving the reduction target will not be easy in construction sectors.
Construction project management mainly centres on time, cost, and quality, while environmental factors such as energy use and its corresponding greenhouse gas emission is not the primary subject of attention. The exact amount of energy consumption in the construction phase is not certain but it is just assumed that it takes up 7-10\% of total energy consumption of all industrial sectors [1]. One of the common obstacles in dealing with environmental factors in construction projects is their innate characteristics of complexity. In order to identify the environmental influences and to evaluate them, various complicated and unpredictable factors need to be considered [2]. On-site Energy use in construction sector is typically multidimensional, complex, and dynamic and involves complicated network of interdependent activities which employs various equipment, machineries, and tools.

Although energy consumption in the construction phase is relatively less than those in operation and maintenance phase, comparatively large amount of energy is spent in relatively short periods of time in construction sites. Considering this characteristic of intensive energy consumption, energy use in construction sites is not a negligible matter. In order to reduce the amount of energy consumption in construction sites, appropriate management strategies are required and it is also needed to develop a model that can exhibit the profiles of the energy use patterns throughout construction periods.

\footnotetext{
${ }^{1}$ Professor, Department of Civil, Safety, and Environmental Engineering, Hankyong National University, Kyeonggi-do, Korea, helden@ @knu.ac.kr (*Corresponding Author)
} 
The modelling methods for the simulation of energy use patterns in construction projects need to incorporate the dynamic and complex characteristics which is inherit in construction projects. In addition, it must be helpful in selecting less energy consuming alternatives in deciding methods and procedures at the design and construction planning stages.

\section{OBJECTIVE}

Previous works related to environmental aspects and energy consumption in construction projects mostly have their subject as energy use during material manufacturing processes or energy efficiency during maintenance and operation, and not many of them are concerned with modelling the energy use patterns directly associated with on-site activities.

This study aims to develop a dynamic simulation modelling methodology that can predict the profile of energy use in construction works and provides an example of earth excavation and hauling activities and shows its corresponding energy use. For the purpose of this, this study identifies the factors that affect the on-site energy use in construction sites and the relationship between on-site activities and procedures and the operations of equipment involving energy consumption. In the modelling example, excavation and lauding, hauling, and dumping activities were included in analysis.

Throughout the whole process of construction work, planning, design, construction, operation, maintenance, and demolishing, energy consumption is carried out for such activities as material manufacturing, transportation of workers and equipment, operation of machineries and equipment, and disposal of waste materials. This study attempts to model the energy use profiles focusing exclusively on the activities regarding the on-site operation of equipment (excavators and dump-trucks in this case) and excluding the energy use for the off-site activities such as manufacturing, transportation, maintenance, and disposal of it. This includes excavators' energy use for the excavation and loading activities and the dump-trucks' hauling, dumping, and returning activities. These activities will be modelled as a dynamic system and corresponding energy use modules will be attached to it. Since energy consumption patterns in construction projects are complex and nonlinear, a system dynamics modelling approach is suited for describing the patterns of on-site energy use profile. Vensim 6.0.0.1 is used for the implementation. The example model of excavation and hauling depicts the patterns of energy use and their hourly profiles. This model can be used for the understanding of energy consumption processes in earth moving work and for selecting energy efficient alternatives of equipment combination at the construction planning stage.

\section{LITERATURE REVIEW}

According to EMAS [3], there are many environmental aspects associated with the construction process and, among them, emission to the air is considered to be most important aspect as the direct and indirect cause of global warming.

Although the embodied energy and greenhouse gas emissions associated with construction are generally considered to be relatively smaller than those required after the completion of buildings (such as for the heating, cooling, and operation of buildings), a significant amount of energy is consumed in construction work every year. European and US figures [1], for example, show the construction portion to be about $7-10 \%$ of total embodied energy. The relative significance of greenhouse gas emissions for that is unknown.

Yan [4] and Seo [5] suggested a system boundary of greenhouse gas emissions in the construction of buildings. Greenhouse gas emissions in the construction sector mostly result from fuel consumption to operate construction equipment and from electricity consumption to provide power to construction tools and offices. Offroad diesel engines used by construction companies feature in a wide variety of equipment, such as loaders, dozers, excavators, graders, and other specialized equipment [6]. To reduce emissions, the US Environmental Protection Agency [7] suggested reduced idling, proper equipment maintenance, driver training, using properly sized equipment, replacing older, fuelefficient equipment with newer models, using low-carbon fuels, and improving employee commuting method. Among these reduction methods, equipment and transportation related features are found to be the major sources of emission.

Lindgren [8] emphasised that a considerable amount of emissions occurs while operating on-site equipment and transporting materials, and in both cases these are related to equipment. Emissions increases in situations such as an abrupt change in engine load and sudden acceleration are critical factors that affect the amount of emission, and are more common circumstances in the operation of construction equipment than in the operation of a passenger vehicle.

Cole [9] estimated greenhouse gas emission and energy use on construction sites. Cole categorised the aspects of greenhouse gas emission and energy use by the construction industry into three processes - worker and equipment transportation, material transportation, and onsite assembly - and examined energy uses and emissions of construction materials such as wood, concrete, and steel for each process. In the case of concrete, for example, it was found that a similar amount of greenhouse gas was emitted at each process, as the ratio is approximately 36:32:31 (on-site equipment use: equipment and material transportation: worker transportation).

Cole also compared the energy use and greenhouse gas emission rom the materials which are selected during the construction process. Embodied energy was defined as the direct and indirect energy used to manufacture, transport, and install building products. In this definition, direct energy refers to the energy consumed in the construction of buildings representing the final transportation and installation of a component or 
assembly, while indirect energy, sharing the largest portion of embodied energy, represents the energy consumed in the production of building materials and their associated transportation. It includes all the energy used for the production of a component, and excludes the energy used for its transportation and installation on-site.

While Cole's study examined worker transportation, equipment and material transportation, and on-site equipment use in order to estimate energy use and emission by the construction sector, KICT (Korea Institute of Construction Technology) report [10] explained energy use as the sum of mechanical equipment use, transportation equipment use, office use, and other facilities use, which excluded worker transportation use.

Energy consumption in construction site consists of electricity for operating equipment and for office use and diesel for transportation and assembly of materials, equipment, and labour. IPCC guideline [11] provides equations to estimate the greenhouse gas emission by these construction activities and Ministry of Land and Marine in Korea also provides estimating methods regards to the activities in construction sites.

Although previous researchers have taken many approaches, all viewed the construction project as whole, rather than as a combined process of activities.

\section{DYNAMIC MODELLING AND ON-SITE CONSTRUCTION PROCESSES}

The conventional network scheduling method regards construction activities as a project and models them in a single-directional arrangement, such as proceeding from start time to finish time. Although this single-directional modelling methodology has its merits in modelling general construction procedures, it does not provide effective and organised modelling solution when it faces repetitive activities. Earth excavation, hauling, dumping, and returning activities are one of the examples of repetitive jobs, as they require a group of equipment performing a series of tasks in a systematic manner. In this type of jobs, it is more convenient to adopt system modelling techniques which allows feedback loop and rotation of activities.

Among all on-site construction processes, energyconsuming processes are those which involve heavy equipment and handle massive materials, and many of them have repetitive and rotational characteristics, such as hauling and lifting the same type of massive materials repetitively using a group of heavy equipment. In modelling such type of processes, it is more reasonable adopting system modelling techniques rather than using conventional network scheduling method.

In order to make the model less complicated, two modules (earth excavation and transportation module and its relevant energy use module). Earth excavation and transportation module is in a loop shape, whereas relevant energy use model is rather one-directional and is dependently connected to the earth excavation and transportation module.

\section{A. Earth excavation and transportation module}

Earth excavation and hauling work is one of the typical examples of systematic and rotational process as it performs the job like the following steps:

Firstly, excavators dig out the earth using their bucket. Secondly, the bucket carries the excavated earth and drops it to the dump-truck which is already standing by at the appropriate position. Thirdly, after repeating the same process until the dump-truck can take no more excavated earth, the dump-truck starts to haul the excavated earth to the dumping site and another dumptruck is then spotting itself to replace the previous one. Fourthly, while the next dump-truck is taking excavated earth from excavators, the leaving dump-truck carries the excavated earth toward the dumping site. In this step, energy consumption is proportional to the shuttling distance of dump-trucks. Fifthly, when the truck arrives at the dumping site, it unloads all the excavated earth on the dumping site. Sixthly, the dump-truck returns to the excavation site. In this step, the truck consumes less energy than in the process of hauling because the box is empty. The final activity is spotting the truck at the appropriate location so that excavators load the excavated earth on the dump-truck. The dump-truck should wait in the queue if there is no room as all excavators are busy loading the earth on the other trucks. These processes can be modelled as a dynamic system, and Figure I shows it.

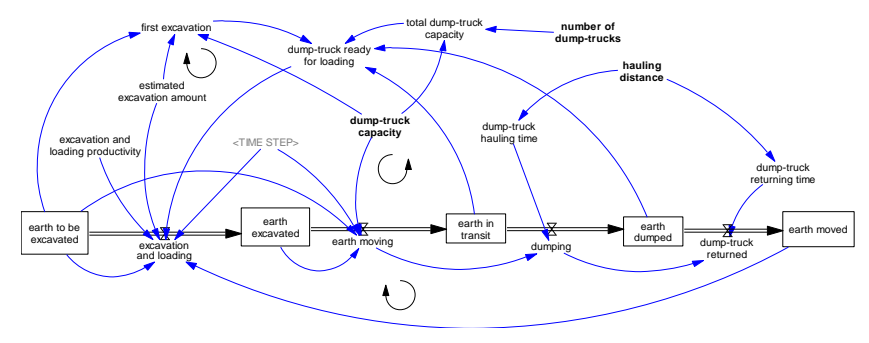

FIGURE I

EARTH MOVING MODULE

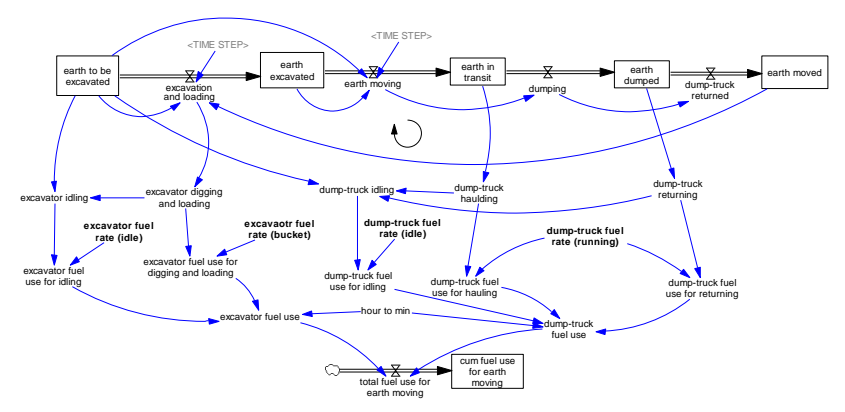

FIGURE II

ENERGY CONSUMPTION MODULE

\section{B. Energy consumption module}

In addition to the excavation and hauling module (Figure I), Figure II shows the energy consumption model. Excavators consume diesel energy in order to excavate and to laud the earth. Dump-trucks also consume diesel energy when they are hauling the excavated earth to the dumping site or returning to the 
excavation site. These machines have different fuel rates according to the task-oriented modes, and the difference varies according to the manufacturers of the machine. Moving dipper buckets to dig and laud needs more energy than idling. As there are very few data on the relationship between the fuel consumption rate and the type of tasks, this study adopts Christopher Frey's study results [12] and regards around one tenth of fuel is consumed in idling situation than in normal situation (Figure IV). In excavation and lauding process, excavators are busy but dump-trucks are idling. If all dump-trucks are away from the dumping site (moving the earth to the dumping site or returning to the excavation site), excavators are idling. The amount of fuel consumed by both machines is estimated and cumulated as a stock variable in the model implementation.

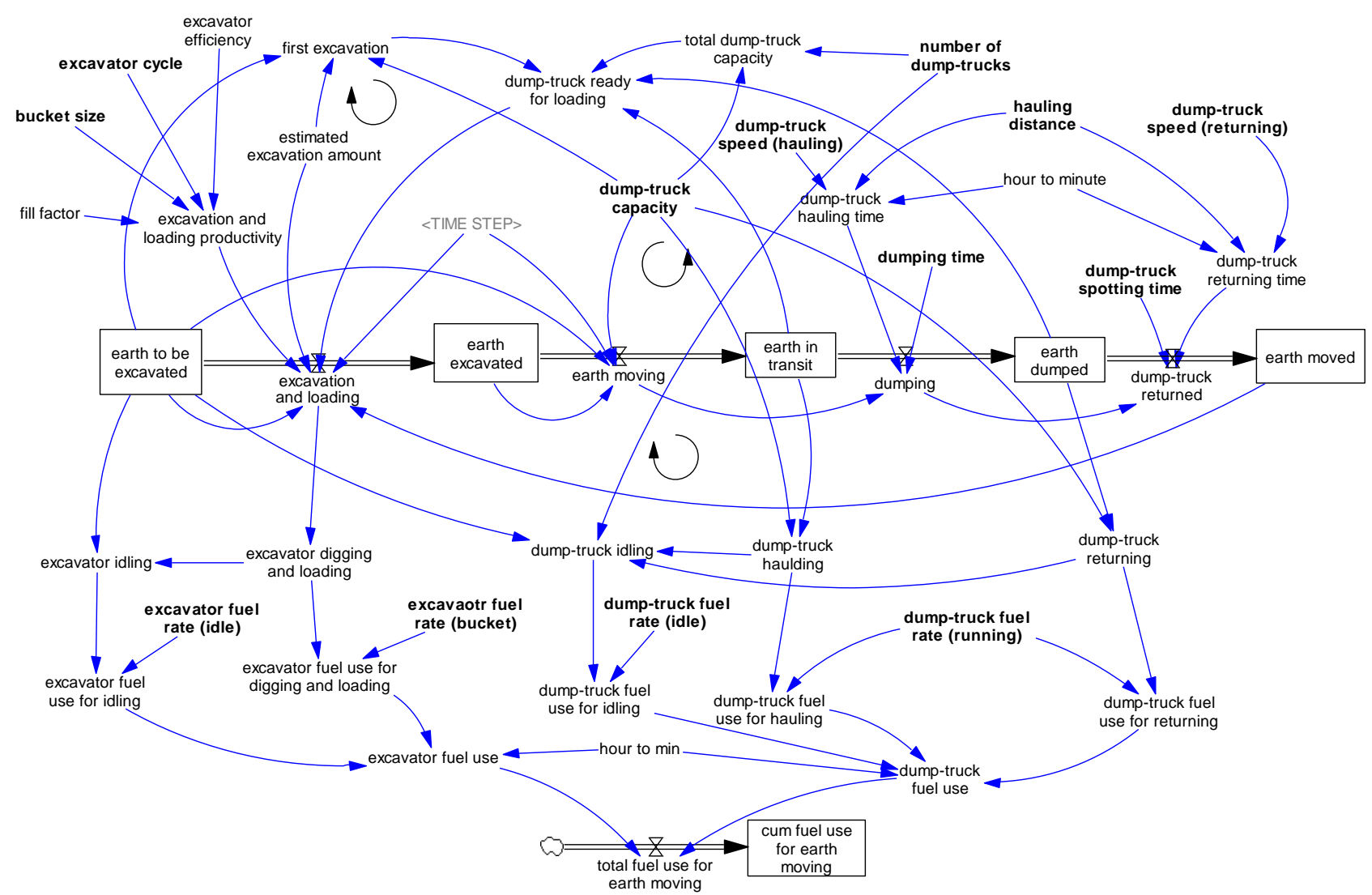

FIGURE III

DiAgRAM FOR THE WHOLE PROCESS

\section{Modelling the whole process}

Combining the two modules produces the following model as shown in Figure III. As the earth moves from the excavation site to the dumping site by the two groups of machine, excavators and dump-trucks, the amount of fuel consumed by those machines are summed and cumulated in the final stock variable.

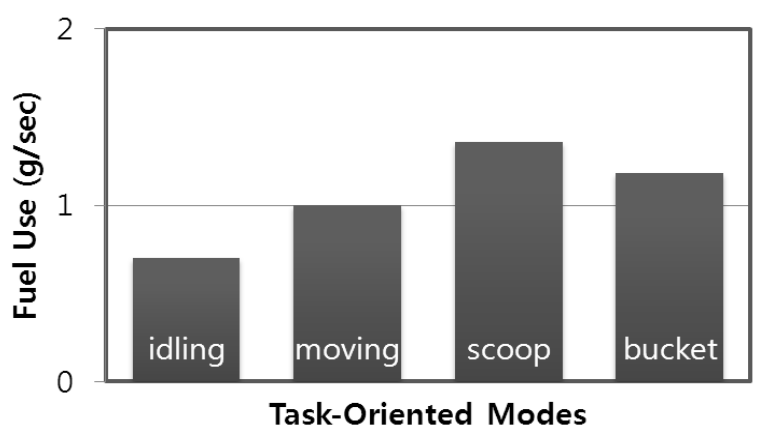

FIGURE IV

Time-Base Fuel Use Rate [12]

\section{Simulation Datasets}

This research adopted the reference data published by Korea Institute of Construction Technology [13]. In order to calculate the duration of each activity, excavator angle and the specific gravity of the earth are assigned to $90^{\circ}$ and $1.6 \mathrm{t} / \mathrm{m}^{3}$, respectively. Excavator bucket sizes, work cycles, fuel rates are listed in Table I and Dumptruck capacities, fuel rates, speed, and dumping and spotting cycles are listed in Table II.

TABLE I

EXCAVATOR Bucket Sizes, Work CyCles, Fuel Rates

\begin{tabular}{c|c|c|c}
\hline $\begin{array}{c}\text { Bucket size } \\
\left(\mathrm{m}^{3}\right)\end{array}$ & $\begin{array}{c}\text { cycle } \\
(\mathrm{sec})\end{array}$ & $\begin{array}{c}\text { fuel rate } \\
(\text { bucketing }) \\
(\ell / \mathrm{hr})\end{array}$ & $\begin{array}{c}\text { fuel rate (idling) } \\
(\ell / \mathrm{hr})\end{array}$ \\
\hline 0.4 & 15 & 9.9 & 0.99 \\
0.7 & 18 & 11.6 & 1.16 \\
1 & 19 & 19.5 & 1.95 \\
2 & 25 & 32.8 & 3.28 \\
\hline
\end{tabular}

Using the model shown in Figure III, this study simulated for 14 sets of alternative conditions with 
different variables, such as bucket size, dump-truck capacity, truck availability, and shuttling distance, as show in Table III.

TABLE II

DUMP-TRUCK FuEl RATE, SPEED, AND TIME

\begin{tabular}{c|c|c|c|c|c|c|c}
\hline \multirow{2}{*}{ capacity } & \multicolumn{2}{|c|}{ fuel rate } & \multicolumn{2}{c|}{ speed } & Dumping & $\begin{array}{c}\text { spotting } \\
\text { time }\end{array}$ \\
\cline { 3 - 8 } & bucket & idle & haul & return & time & min \\
\hline ton & $\mathrm{m}^{3}$ & $\ell / \mathrm{hr}$ & $\ell / \mathrm{hr}$ & $\mathrm{km} / \mathrm{hr}$ & $\mathrm{km} / \mathrm{hr}$ & Min & m \\
\hline 15 & 11.25 & 15.9 & 1.59 & 15 & 20 & 0.8 & 0.65 \\
\hline 20 & 15 & 20 & 2 & 15 & 20 & 0.8 & 0.65 \\
\hline 24 & 18 & 23 & 2.3 & 15 & 20 & 0.8 & 0.65 \\
\hline
\end{tabular}

TABLE III

DATASETS FOR SIMULATION

\begin{tabular}{c|c|c|c|c}
\hline No & $\begin{array}{l}\text { Excavator } \\
\text { Bucket size } \\
\left(\mathrm{m}^{3}\right)\end{array}$ & $\begin{array}{l}\text { Dump-truck } \\
\text { capacity } \\
\text { (ton) }\end{array}$ & $\begin{array}{l}\text { number } \\
\text { truck(s) }\end{array}$ & $\begin{array}{l}\text { shuttling } \\
\text { distance } \\
(\mathrm{km})\end{array}$ \\
\hline$(01)$ & 2.0 & 15 & 2 & 2 \\
$(02)$ & 2.0 & 20 & 2 & 2 \\
$(03)$ & 2.0 & 24 & 2 & 2 \\
$(04)$ & 2.0 & 15 & 2 & 2 \\
$(05)$ & 1.0 & 15 & 2 & 2 \\
$(06)$ & 0.7 & 15 & 2 & 2 \\
$(07)$ & 2.0 & 15 & 2 & 2 \\
$(08)$ & 2.0 & 15 & 3 & 2 \\
$(09)$ & 2.0 & 15 & 4 & 2 \\
$(10)$ & 2.0 & 15 & 6 & 2 \\
$(11)$ & 2.0 & 15 & 6 & 2 \\
$(12)$ & 2.0 & 15 & 6 & 5 \\
$(13)$ & 2.0 & 15 & 6 & 8 \\
$(14)$ & 2.0 & 15 &
\end{tabular}

\section{RESULTS}

Model behaviour after implementation is presented in Figures V VIII.

\section{A. The Effect of Dump Truck Capacity on Work Duration and Fuel Use}

After implementation of the dump-trucks with three different capacities, the behaviour of the model (Figure V) shows slight reduction in both energy use and work duration when larger capacity trucks are applied.

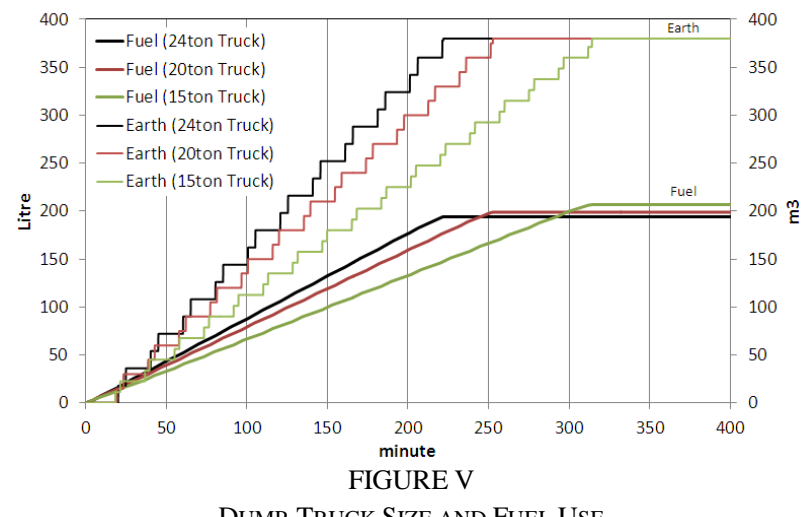

DUMP-TRUCK SIZE AND FUEL USE

\section{B. The Effect of Excavator Bucket Size on Work Duration and Fuel Use}

The behaviour of the model after implementation of the excavators with three different dipper bucket sizes (Figure VI) shows slight reduction in energy use but a little increase in work duration when smaller buckets are adopted.

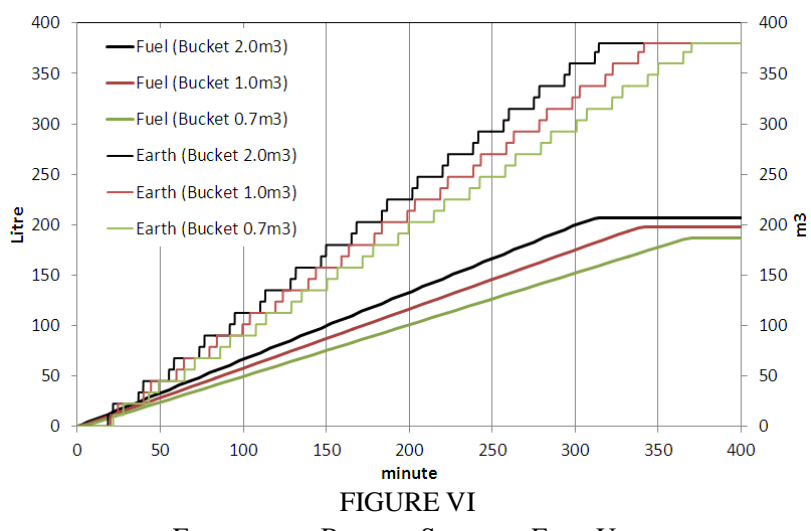

EXCAVATOR BUCKET SIZE AND FUEL USE

C. The Effect of Number of Dump-Trucks on Work Duration and Fuel Use

The behaviour of the model after implementation of varying number of dump-trucks (Figure VII) shows slight less energy use and a significant reduction in work duration when more number of trucks were mobilised.

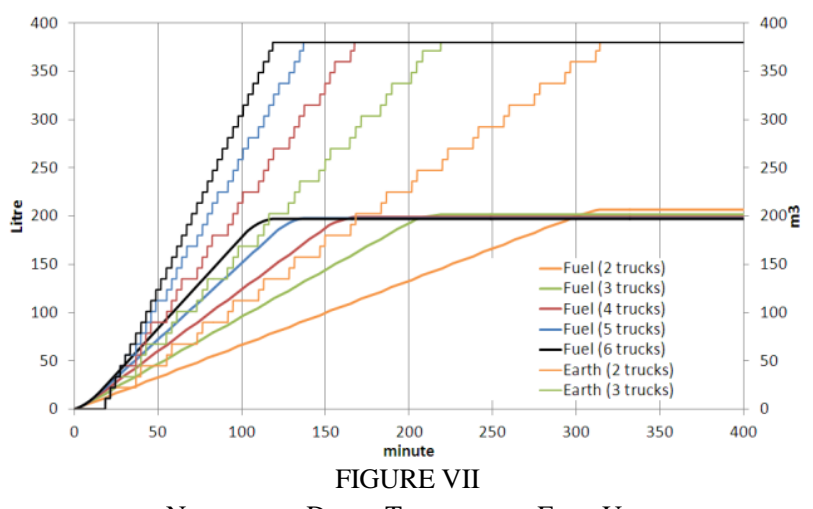

NUMBER OF DUMP-TRUCKS AND FUEL USE

D. The effect of shuttling distance of dump-truck on work duration and fuel use

The behaviour of the model after implementation of varying distances of hauling (Figure VIII) shows significant increase both in energy use and in work duration when the shuttling distance becomes longer.

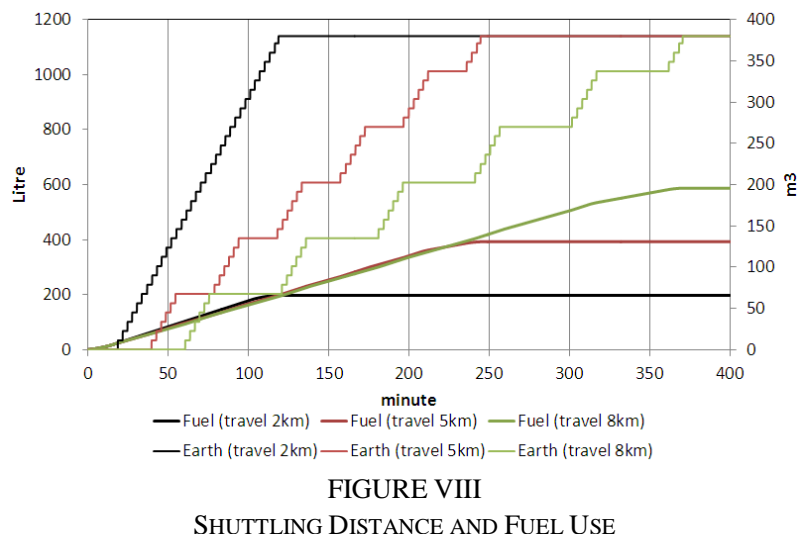




\section{DISCUSSION}

Based on the simulation results, this study analysed energy efficiency of each alternatives, i.e. fuel use per earth moving, and the outcome is shown in Figures IX XII.

\section{A. Dump Truck Capacity and Energy Efficiency}

Firstly, if dump-truck capacity increases, energy efficiency decreases. It means hauling larger amount of earth at one go reduces fuel efficiency rather than shuttling more time with smaller trucks. As less shuttling time means saving work duration, larger dump-truck can save both energy and work duration.

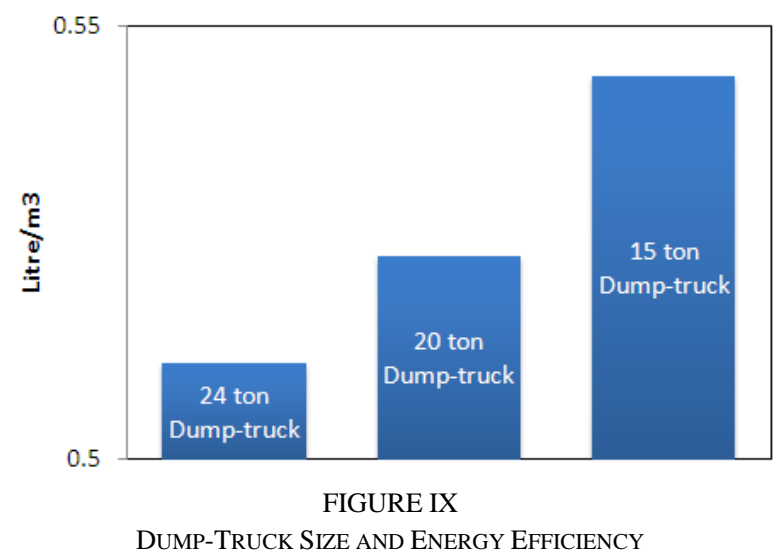

\section{B. Bucket Size and Energy Efficiency}

Secondly, fuel efficiency slightly increases if smaller buckets are used. It stretches work duration a bit longer when smaller buckets are used. Smaller buckets can decrease digging cycle time, but increases the frequency.

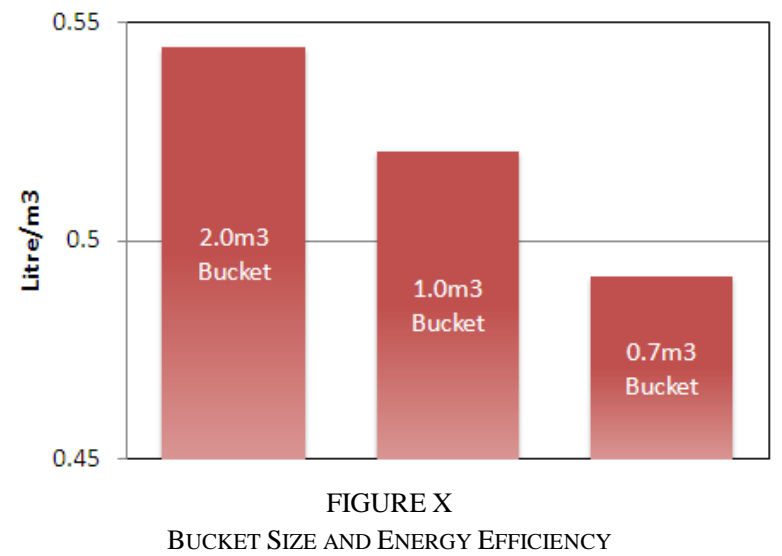

\section{Number of Trucks and Energy Efficiency}

Thirdly, assigning many dump-trucks can save both energy efficiency and work duration. If there is enough number of dump-trucks available, excavator idling time can be saved, which may help enhancing excavator fuel efficiency.

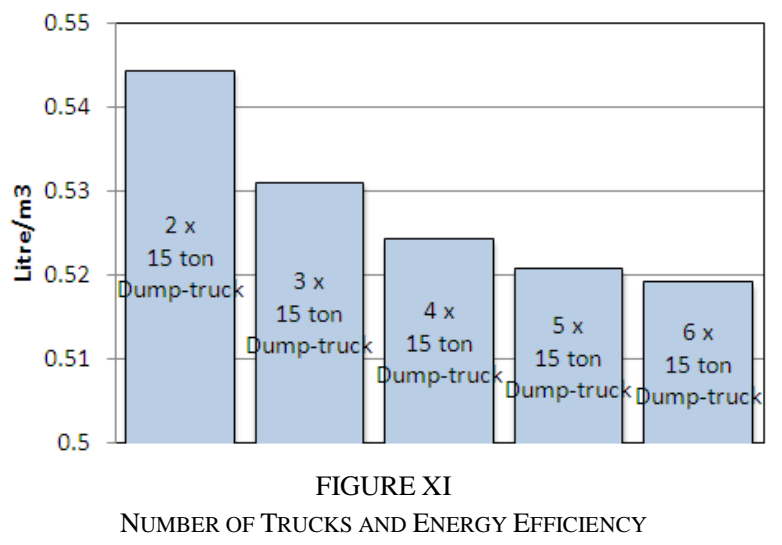

\section{Shuttling distance and energy efficiency.}

Finally, shuttling distance of dump-truck is surely the most crucial factor that affects energy efficiency and work duration. Rather than choosing energy efficient machines and adopting economic construction method, it is much more helpful to find nearest dumping site for saving energy and time.

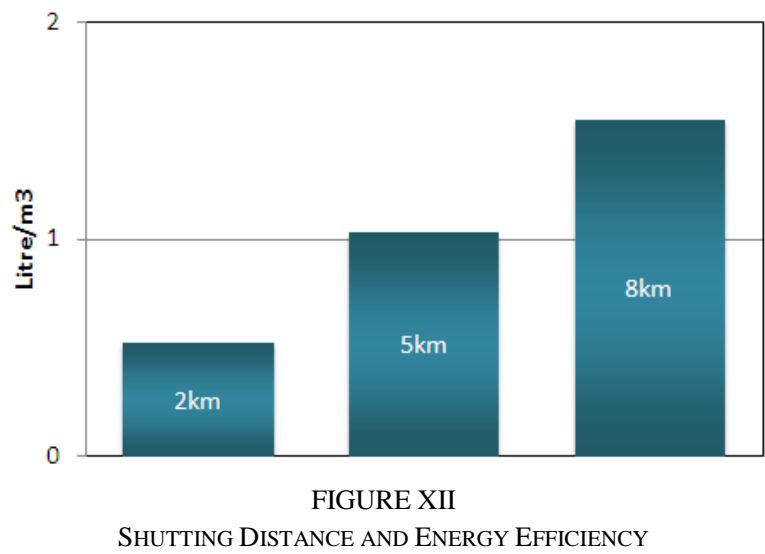

VII. CONCLUSION

For the purpose of analyse on-site energy use patterns in construction projects, this study simulated fuel consumption profiles of construction equipment using system dynamics modelling techniques. The earth excavation and hauling work and its corresponding energy use was modelled and showed its on-site energy use patterns with varying conditions. Through extensive analysis of the simulation result, the model derived the earth movement and its corresponding energy use patterns by earth excavation and hauling work. This simulation model can be used in selecting more fuel efficient combination of excavating and hauling equipment and in estimating its corresponding energy use patterns at the planning stage. Findings of this study are as follows:

(1) From the simulation results of 14 different conditions, the model showed which condition provides more energy-efficient outcome: energy efficiency gets higher when bigger capacity dump-trucks, smaller bucket-sized excavators, larger number of dump-trucks and shorter shuttling distance are selected. 
(2) As conventional scheduling techniques aims to save time and cost, it is not easy to combine energyefficiency or greenhouse gas reduction targets with it. The results of this study have shown how to obtain energy-efficient and time-saving alternatives of equipment combination.

(3) Due to the complexity of construction project, it is not adequate to estimate energy consumption and greenhouse gas emission by just applying equations provided by estimating guides such as IPCC guides. The dynamic system model presented in this study provided not only the amount energy consumed but the time-based profiles of energy consumption as well, which will be helpful to generate more reliable estimation results.

If the energy profile estimation model is applied at the construction planning stage, it can be utilised to compare alternative of equipment combination and to generate more energy-efficient and time-saving alternatives and eventually contribute energy-saving and greenhouse gas reduction in construction sites.

\section{ACKNOWLEDGEMENTS}

Note: This paper was originally published as the conference paper in the ICCEPM 2013 and awarded as one of the best papers. Through a rigorous review process, the paper has been invited to be a special version of JCEPM.

\section{REFERENCES}

[1] R.J. Cole, D. Rousseau, "Environmental auditing for building construction: Energy and air pollution indices for building materials", Building and Environment, vol. 27, no. 1, pp. 23-30, 1992.

[2] M. Gangolells, "Assessing Concerns of Interested Parties when Predicting the Significance of Environmental Impacts Related to the Construction Process of Residential Buildings," Building and Environment, vol. 46, NO. 11, pp. 1023-1037, 2011.

[3] European Parliament and the Council of the European Union, "Regulation (EC) No. 761/2001 of the European Parliament and of the Council allowing voluntary participation by organizations in a Community eco-management and audit scheme (EMAS)", Official Journal of the European Communities, L 114, 2001.

[4] H. Yan, "Greenhouse Gas Emissions in Building Construction: A Case Study of One Peking in Hong Kong", Building and Environment, vol. 45, no. 4, pp. 949-955, 2010

[5] S. Seo, Y. Hwang, "Estimation of $\mathrm{CO}_{2}$ Emissions in Life Cycle of Residential Buildings", Journal of Construction Engineering and Management, vol. 127, no. 5, pp. 414-418, 2001.

[6] P. Truitt, "Quantifying Greenhouse Gas Emissions from Key Industrial Sectors in the United States", US Environmental Protection Agency, p.5-1, 2008.

[7] P. Truitt, "Potential for Reducing Greenhouse Gas Emissions in the Construction Sector", US Environmental Protection Agency, p. 12, 2009.

[8] M. Lindgren, "Evaluation of Factors Influencing Emissions from Tractors and Construction Equipment during Realistic Work Operations Using Diesel Fuel and Bio-Fuels as Substitute", Biosystems Engineering, vol. 107, no. 2, pp. 123-130, 2010

[9] R.J. Cole, "Energy and Greenhouse Gas Emissions Associated With the Construction of Alternative Structural Systems," Building and Environment, vol. 23, no. 2, pp. 224-237, 1999.

[10] S.E. Lee, "The Environmental Load Unit Composition and Program Development for LCA of Building: The Construction of Method With LCA for Estimating Environmental Building”, Korea Institute of Construction Technology, 2004.

[11] The Intergovernmental Panel on Climate Change (IPCC) 2006, "2006 IPCC Guidelines for National Greenhouse Gas
Inventories", Eds. H.S. Eggleston, L. Buendia, K. Miwa, T. Ngara, K. Tanabe, Institute for Global Environmental Strategies (IGES), Hayama, Japan, p.11, 2006.

[12] H.C. Frey, W. Rasdorf, K. Kim, S.-H. Pang, P. Lewis, S. Abolhassani, "Real-World Duty Cycles and Utilization for Construction Equipment in North Carolina, North Carolina State University", North Carolina Department of Transportation, 2008.

[13] Korea Institute of Construction Technology, "Construction estimating standards", Ministry of Land and Marine, 2012. 